\title{
Epistemics with Attitude
}

\author{
Pranav Anand Valentine Hacquard \\ UCSC UMD
}

\section{Two puzzles about attitude verbs and epistemic modals}

In the Hintikkan tradition, attitude verbs are treated uniformly as universal quantifiers over possible worlds, where the sole difference between various attitudes is in the accessibility relation that determines the set of worlds they quantify over. Believe, want and say quantify respectively over worlds compatible with the beliefs, desires, claims of the attitude holder. In this paper, we discuss two distributional puzzles which argue against such a uniform picture. The first puzzle concerns the distribution of epistemic modals in the scope of attitudes: epistemics can appear in the complement of certain attitude verbs, but not others:

a. John \{believes, argues, assumed that the Earth might be flat.

b. *John \{hopes, wishes, commanded that the Earth might be flat.

Which attitudes allow epistemics, and more generally, what are the conditions for licensing an epistemic modal? We will argue that epistemics need to be licensed by operators that have propositional content, and present a taxonomy of attitudes that differentiates two major classes: attitudes that have associated propositional content and attitudes that do not. We identify the first class with those which Stalnaker (1984) termed attitudes of acceptance (i.e., attitudes said to be correct whenever their complement is true), illustrated in (1a), and the second class with those verbs that involve an alternative-based semantics (cf. Villalta 2000), which include bouletics and commands, illustrated in (1b).

The second puzzle, which we introduce in section 3.1, focuses on attitudes that do license epistemics (attitudes of acceptance) and shows that they split into two categories based on the type of epistemics they license: doxastic attitudes (e.g., believe, think) license subjective epistemics, proffering attitudes (e.g., argue, assume) license objective epistemics. More generally, we will show that doxastics induce a subjective, while profferings induce an objective stance on the proposition expressed by their complement. We argue that the difference in subjectivity results from the fact that, while doxastics are mere reports of static

Many thanks to D. Altshuler, J. Anderssen, R. Bhatt, A. Brasovaneau, E. Eaker, D. Farkas, K. von Fintel, I. Frana, C. Gunlogson, E. Herburger, G. Katz, N. Klinedinst, B. Ladusaw, P. Menendez-Benito, P. Portner, A. Rubinstein, A. Salanova, and P. Schlenker for fruitful comments, as well as the participants of Hacquard's Spring 2008 UMD Semantics Seminar and audiences at Universität Tübingen, UCSC S-Circle, SALT 18, and SPE. 
states of mind, profferings are reports of discourse moves, that is, attempts to update the common ground.

The embedding and subjectivity differences across attitudes each indicate that epistemics are sensitive to the type of event an attitude predicate reports, a fact traditional analyses cannot explain. Instead, we will adopt the proposal of Hacquard (2006), in which all modals are relativized to event variables present in the syntactic structure; this system is introduced in section 2, which also accounts for the inability of epistemics to appear in bouletic/command environments. In section 3, we turn to attitudes of acceptance, and show how an event-relative treatment of epistemics explains the subjectivity puzzle and discuss the architectural implications for the event-relative framework. Notably we show how this system renders CP complements properties of events. Section 4 discusses differences between the semantics of discourse moves and their reports.

\section{Epistemic modals}

One of the main questions from the epistemic literature is whether epistemics should be treated on a par with other modals ('roots'). A major difficulty for a unified account is that epistemics are notoriously hard to embed (under tense, negation, quantifiers, in questions, in antecedents of conditionals, complements of attitude verbs...). This fact has lead many to postulate that, unlike other modals, epistemics do not contribute to the truth conditional content of the sentence they combine with, but instead, express a 'comment', 'confidence', or 'probability assignment' from the speaker regarding the sentence (cf. Halliday 1970, Palmer 1986, Drubig 2001, Swanson 2006, a.o.). Contributing to this debate, Lyons (1977) puts forth a distinction among epistemics in terms of subjectivity, and claims that only subjective epistemics lack truth conditional content, while objective epistemics receive an ordinary modal semantics. Meaning-wise, the difference between subjective and objective epistemics lies in the type of evidence that epistemics invoke: someone's (often the speaker) personal (and perhaps fallible) evidence for the former, and more reliable or complete evidence, taken to be accepted throughout the relevant community for the latter (cf. Papafragou 2006, Portner, 2008, Fintel and Gillies 2007, Tancredi 2007).

While the distribution of epistemics is restricted in non trivial ways, it appears that even subjective epistemics can appear in certain attitude contexts (Portner, 2008). The modal in (2) seems to express a subjective epistemic possibility based on John's subjective beliefs:

John believes that it might be raining.

Thus, subjectivity doesn't seem to be a predictor for the embedability of epistemic modals. It does, however, yield grammatical differences, as shown by Tancredi 
(2007), who proposes an independent grammatical test for objective modality, based on von Fintel and Iatridou's (2003) work on the scopal interaction of epistemics with quantifiers. Fintel and Iatridou (2003) show that strong quantifiers cannot take scope over an epistemic modal. This is their Epistemic Containment Principle (ECP), whereby a strong quantifier cannot bind its trace across an epistemic, as illustrated in the example below:

\#Every guest might be the murderer.

a. \#It is possible that all guests are the murderer $\quad \diamond \forall$

b. *For each guest $x$, it is possible that $x$ is the murderer $\quad * \forall>\searrow$

The only possible interpretation for (3) is one where 'every' takes scope below the modal (a), which is infelicitous (unless we talk about a collective murder). Tancredi (2007) observes that the ECP only holds of subjective epistemics (which he takes to be the default epistemic interpretation). When one forces an objective reading (via an overt modifier such as objectively speaking), the felicitous interpretation (b) where 'every' scopes over the modal becomes available:

(4) Objectively speaking, every guest might be the murderer.

a. \#It is possible that all guests are the murderer $\quad \diamond>\forall$

b. For each guest $x$, it is possible that $x$ is the murderer $\quad * \forall>\searrow$

We assume that epistemics should be treated on a par with other modals: they can embed (regardless of subjectivity) and contribute truth conditional content. However, their distribution seems to be restricted by particular licensing conditions determined by the grammatical environment in which they appear. In this section, we provide a semantics for epistemics that can account for their limited distribution. We adopt Hacquard's (2006) proposal, according to which modals are relative to an event of evaluation, and where an epistemic accessibility relation can only be licensed by a contentful event, i.e., an event with associated propositional content, which only speech and certain attitude events have. This propositional content will further determine the particular epistemic flavor of the modal, in particular, whether it is understood as subjective or objective.

\subsection{An event-relative semantics for modals (Hacquard 2006, 2008)}

Hacquard (2006) proposes to reconcile epistemics' tendency to scope high (in particular higher than tense) with a unified account of modality in the Kratzerian tradition. As in Kratzer (1981), there is just one possibility and one necessity modal. Each is treated as a quantifier over possible worlds, with the particular flavor of modality arising from contextually provided accessibility relations $f$. Hacquard departs from Kratzer by having modals be relative to an event (rather 
than a world) of evaluation:

$$
\llbracket \mathrm{can} \rrbracket=\lambda \mathrm{f} \lambda \mathrm{q} \exists \mathrm{w}^{\prime} \in \mathrm{f}(\mathbf{e}): \mathrm{q}\left(\mathrm{w}^{\prime}\right)=1
$$

There are two positions in which a modal can appear within a clause: right above tense (high modals), or right above VP (low modals). Hacquard assumes that a modal is relativized to the closest c-commanding event, and thus a modal that appears above tense is relative to the speech event (and hence the speaker and the speech time), unless it is in the complement of an attitude, in which case, it is relative to the attitude event (and hence the attitude holder and the attitude time):
a. It might be raining.
Rain is possible for me right now.

b. John believed that it might be raining.

Rain was possible for John at his (past) believing time.

\#John believed that rain \{was/is possible for me, is possible for him\}

As (6) demonstrates, modals are systematically relative to time/individual pairs (speaker/speech time or attitude holder/attitude time for epistemics, and VP participants/VP time for root modals), which correspond to the running time and participants of the closest event. Under standard treatments, this correlation must be stipulated, while closest-event relativity predicts it directly. To capture the fact that only high modals can receive an epistemic interpretation (low modals receive root interpretations), Hacquard (2006) proposes that an epistemic accessibility relation can only be licensed by a contentful event, that is, an event with associated propositional content, which, she argues, only speech and attitude events have. In the following entry for the epistemic accessibility relation, CONTENT(e) is the function that picks out the set of propositions associated with the event $e$ :

$$
\mathrm{f}_{\text {epistemic }}(\mathrm{e})=\lambda \mathrm{w}^{\prime} . \mathrm{w}^{\prime} \text { is compatible with } \operatorname{CONTENT}(\mathrm{e})
$$

Hacquard (2008) assumes that the speech event $\mathrm{e}_{0}$ is syntactically represented in topmost position and determines the nature of the utterance. For a declarative sentence, $\mathrm{e}_{0}$ is an asserting event. Following Alonso-Ovalle and Menendez-Benito (2008), Hacquard assumes that assertions are implicitly modalized and quantify over the speaker's doxastic alternatives: $\mathrm{e}_{0}$ has associated 'content', which consists of its holder's doxastic alternatives (or 'acceptance' state):

$$
\begin{aligned}
& \llbracket A S S E R T \mathrm{e}_{0} \rrbracket=\lambda \mathrm{p} . \lambda \mathrm{e}_{0} . \forall \mathrm{w}^{\prime} \in \cap \operatorname{CON}\left(\mathrm{e}_{0}\right)\left[\mathrm{p}\left(\mathrm{w}^{\prime}\right)\right] \\
& \text { where } \cap \operatorname{CON}\left(\mathrm{e}_{0}\right)=\operatorname{DOX}\left(\mathrm{tx} \operatorname{Holder}\left(\mathrm{x}, \mathrm{e}_{0}\right), \operatorname{WORLD}\left(\mathrm{e}_{0}\right)\right) \\
& \text { and } \mathrm{ix} \operatorname{Holder}\left(\mathrm{x}, \mathrm{e}_{0}\right)=\text { speaker }
\end{aligned}
$$


Hacquard assumes that a default root event binder $\lambda \mathrm{e}_{0}$ (in the spirit of Percus 2000) binds the event variable of ASSERT. Thus, in this framework, a sentence is technically always relative to an event of evaluation. World-relativity is mediated by ASSERT:
a. It is raining.
b. $\lambda \mathrm{e}_{0}\left[\mathrm{CP}\right.$ ASSERT $\mathrm{e}_{0}[\mathrm{TP}$ it is raining] ] ]
c. $\forall \mathrm{w}^{\prime} \in \cap \operatorname{CON}\left(\mathrm{e}_{0}\right)\left[\right.$ it is raining( $\left.\left(\mathrm{w}^{\prime}\right)\right]$
e. In all worlds compatible with speaker's dox alternatives it is raining.

$\lambda \mathrm{e}_{0}$ may also bind the event variable of a modal, enabling speech event content to relativize an epistemic modal, as shown below. Both ASSERT and the modal quantify over the worlds compatible with the content of the speech event; this results in a layer of vacuous quantification, so that (c) is equivalent to (d):
a. It might be raining.
b. $\lambda \mathrm{e}_{0}$ [CP ASSERT $\mathrm{e}_{0}$ [ModP might $\mathrm{f}\left(\mathrm{e}_{0}\right)$ [TP be raining] ] ]
c. $\forall \mathrm{w}^{\prime} \in \cap \operatorname{CON}\left(\mathrm{e}_{0}\right)\left[\exists \mathrm{w}^{\prime \prime} \in \cap \operatorname{CON}\left(\mathrm{e}_{0}\right)\right.$ it is raining( $\left.\left(\mathrm{w}^{\prime \prime}\right)\right]$
d. $\exists w^{\prime} \in \cap \operatorname{CON}\left(\mathrm{e}_{0}\right)$ [it is raining( $\left.\left.\mathrm{w}^{\prime}\right)\right]$
e. In some world compatible with speaker's dox alternatives it is raining.

With respect to attitude events, Hacquard $(2006,2008)$ argues that the CONTENT function is also at work. As verbs, attitude verbs are treated as predicates of events (cf. Davidson 1967). However, the event they describe is special in that it has 'content', i.e., a set of propositions (e.g., beliefs) associated with it. Hacquard recasts the standard Hintikka semantics of doxastic verbs, which involve quantification over doxastic alternatives of the subject, in event terms by using the CONTENT function. CON(e) picks out directly the set of propositions that make up the attitude:

$$
\begin{aligned}
\llbracket \text { believe } \rrbracket= & \lambda \mathrm{e} \cdot \lambda \mathrm{p} . \lambda \mathrm{x} . \lambda \mathrm{w} . \operatorname{Holder}(\mathrm{x}, \mathrm{e}) \& \operatorname{belief}^{\prime}(\mathrm{e}, \mathrm{w}) \& \forall \mathrm{w}^{\prime} \in \cap \operatorname{CoN}(\mathrm{e}) \\
& {\left[\mathrm{p}\left(\mathrm{w}^{\prime}\right)=1\right], \text { where } \cap \operatorname{con}(\mathrm{e})=\operatorname{DOx}(\mathrm{tx} \operatorname{Holder}(\mathrm{x}, \mathrm{e}), \mathrm{w}) }
\end{aligned}
$$

Like speech events, the content of a doxastic can license an epistemic, as shown below. The modal's event variable (which was bound by $\lambda \mathrm{e}_{0}$ in matrix contexts) is now bound by matrix Aspect, i.e., the event quantifier responsible for binding the attitude event. Again this results in a layer of vacuous quantification $((c) \equiv(d))$ :
a. John believes that it might be raining.
b. ... Aspect $t_{1}$ John believe $\mathrm{e}_{1}$ [ModP might $\mathrm{f}\left(\mathrm{e}_{1}\right)$ [TP be raining] ] ]
c. $\exists \mathrm{e}_{1}$ : belief' $\left(\mathrm{e}_{1}, \mathrm{w}\right) \ldots \forall \mathrm{w}^{\prime} \in \cap \operatorname{CON}\left(\mathrm{e}_{1}\right)\left[\exists \mathrm{w}^{\prime} \in \cap \operatorname{CON}\left(\mathrm{e}_{1}\right)\right.$ : $\left.\operatorname{raining}\left(\mathrm{w}^{\prime \prime}\right)\right]$
d. $\exists \mathrm{e}_{1}$ : belief' $\left(\mathrm{e}_{1}, \mathrm{w}\right) \ldots \exists \mathrm{w}^{\prime} \in \cap \operatorname{CON}\left(\mathrm{e}_{1}\right)$ [it is raining $\left.\left(\mathrm{w}^{\prime}\right)\right]$
e. In some world compatible with John's dox alternatives it is raining. 
Note that this account departs from more traditional ones where epistemics are stated in terms of knowledge. One advantage is that it explains why, in examples like (2), the modal seems to express a possibility given what John believes rather than what he knows. For matrix contexts, it conforms to Tancredi's (2007) observation that subjective epistemics are really doxastic and do not involve knowledge. This account further predicts that the particular 'epistemic' interpretation a modal receives will be anaphoric to the content of the attitude that embeds it. In (10) and (12) given that both events are belief states, the modals quantify in a private, subjective intensional space. We predict that the subjective/objective contrast will arise from the subjectivity of the event contents themselves. We turn to the subjectivity of attitude events in section 3 .

This account makes a further prediction: an epistemic will be licensed whenever it is anchored to a contentful event. This explains why low modals (i.e., modals interpreted below tense) can only receive a root interpretation. It cannot, however, explain our original puzzle: If epistemics are licensed by contentful events, why can't they appear in all attitude contexts?

\subsection{Addressing the epistemic distribution puzzle}

Recall from the introduction that epistemic modals can only appear in the complement of attitudes of acceptance, i.e., attitudes said to be correct whenever the proposition expressed by their complement is true (Stalnaker 1984, p.79). They cannot, on the other hand, appear under bouletics or commands:

(13) a. John \{believes, argues, assumed that the Earth might be flat.

b. *John \{hopes, wishes, commanded\} that the Earth might be flat.

It thus appears our CONTENT function is only defined when $e$ is an acceptance, and not a bouletic or a command ${ }^{1}$. We propose that the reason bouletics/ commands cannot license epistemics is that they lack propositional content.

There are independent reasons to believe that bouletics and commands are fundamentally different from attitudes of acceptance (cf. Farkas 1992, Villalta 2000, Moltmann 2003, a.o.), as, for instance, the fact that their complements take subjunctive, rather than indicative mood, in languages that have the relevant contrast. However, if bouletics/commands do not invoke propositional content, how can they embed propositions? Here, we adopt Villalta's (2000) proposal that

\footnotetext{
${ }^{1}$ Emotives are not instances of acceptance (no notion of correctness), predicting that they cannot embed epistemics. The facts require more research:

(i) a. John \{\#regrets, is afraid, is happy\} that the Earth might be flat.

b. John \{\#regrets, \#is afraid, \#is happy\} that the Earth must be flat.
} 
attitudes like want involve a comparative semantics of contextually provided alternatives, where the proposition expressed by the complement is ordered with respect to these alternatives. In her lexical entry below, want carries an index $\mathrm{C}$ that stands for a variable anaphoric to a contextually-determined set of propositions (cf. Rooth 1985, Fintel 1994):

$\llbracket$ want $_{\mathrm{C}} \rrbracket^{\mathrm{g}}(\mathrm{p})(\mathrm{a})(\mathrm{w})=1$ iff $\forall \mathrm{q} \in \mathrm{g}(\mathrm{C}): \mathrm{p}<_{\mathrm{a}, \mathrm{w}} \mathrm{q}$, where $<_{\mathrm{x}, \mathrm{w}}$ is defined as follows:

(i) for any $\mathrm{w}, \mathrm{w}^{\prime}, \mathrm{w}^{\prime}, \mathrm{w}^{\prime}<_{\mathrm{x}, \mathrm{w}} \mathrm{W}$ ', iff $\mathrm{w}^{\prime}$ is more desirable to $\mathrm{x}$ in $\mathrm{w}$ than $\mathrm{w}$ ',

(ii) for any $\mathrm{p} \subseteq \mathrm{W}, \mathrm{q} \subseteq \mathrm{W}, \mathrm{p}<_{\mathrm{x}, \mathrm{w}} \mathrm{q}$ iff for $\forall \mathrm{w}^{\prime}{ }^{\prime} \in \mathrm{q}, \exists \mathrm{w}{ }^{\prime} \in \mathrm{p}$ s.t. $\mathrm{w}^{\prime}<_{\mathrm{x}, \mathrm{w}} \mathrm{W}$, , and it is not the case that for all $\mathrm{w}^{\prime} \in \mathrm{p}, \exists \mathrm{w}$ ' $\in \mathrm{q}$ s.t. $\mathrm{w}^{\prime}{ }^{\prime}<_{\mathrm{x}, \mathrm{w}} \mathrm{w}$ '.

It is thus possible to give bouletics/commands an adequate semantics without propositional content, making sense of the fact that they cannot embed epistemics.

\section{Decomposing attitudes of acceptance}

In the previous section, we demonstrated that only some attitude verbs, attitudes of acceptance, permit epistemics in their scope. In this section, we will put attitudes of acceptance under the microscope and show that they further divide. We will begin with three behavioral distinctions between doxastic attitudes (believe, think, know) and proffering attitudes (claim, argue, demonstrate). We will first consider how epistemics in the scope of various acceptance attitudes are interpreted. Based on their behavior with regard to the ECP, we will argue that doxastics force a subjective interpretation of epistemics in their scope, while profferings force an objective interpretation. We will then show that this objectivity split is consistent when we trade predicates of personal taste for epistemics. Finally, we will show that doxastics and profferings differ in the restrictions on their attitude holder argument - while doxastics require their attitude holders to be sentient, profferings do not. Having motivated the need for differentiating the two classes of acceptance attitudes, we will locate the source of these differences in the types of events the two classes of attitudes ascribe: while doxastic attitude predicates report beliefs, profferings report discourse moves which attempt to settle an issue. We argue that the objectivity of profferings is due to the evaluation of the proposition in the projected common ground of the discourse move, where the issue has been adopted by all participants.

\subsection{Subjectivity in attitudes of acceptance}

We begin our examination of attitudes of acceptance by recalling an observation about how unembedded epistemics are interpreted. As we discussed in section 2, 
while quantifiers resist interpretation above epistemics (Fintel and Iatridou 2003), that ECP effect is obviated in the presence of the tag objectively speaking, which forces epistemics to be interpreted objectively (Tancredi 2007):

(15) \#Every guest might be the murderer.

a. \#It is possible that all guests are the murderer

b. *For each guest $x$, it is possible that $x$ is the murderer

(16) Objectively speaking, every guest might be the murderer.

a. \#It is possible that all guests are the murderer

b. For each guest $\mathrm{x}$, it is possible that $\mathrm{x}$ is the murderer

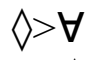

The contrast in (15)-(16) thus provides a diagnostic for subjectivity of stance; a subjective stance correlates with ECP obeying epistemics, and an objective one with ECP obviation. For the purposes of this paper, we will not attempt to derive the correlation between subjectivity and the ECP (see Tancredi 2007 for one attempt) ${ }^{2}$. With this diagnostic in hand, consider the behavior of doxastic and proffering complements:

a. \#Holmes believed that every guest might be the murderer.

Intended: $\mathrm{H}$. believed each had the possibility to be the murderer.

b. Holmes \{assumed, implied\} that every guest might be the murderer.

While doxastic complements pattern with ordinary assertions, proffering attitudes show the same obviation abilities as objectively speaking, suggesting that they likewise induce an objective stance in the complement clause.

A similar differentiation occurs in the according to $X$ construction. When $X$ denotes a doxastic state, epistemics obey the ECP, while when $X$ denotes a proffering event, they show obedience: ${ }^{3}$

(18) a. \#According to John's beliefs, everyone might be the murderer.

b. According to John's claim, everyone might be the murderer.

\footnotetext{
${ }^{2}$ We should note the ECP can be obviated by modification of the quantifier, including focus, use of a strong distributor or a domain widener (i); Furthermore, the ECP seems to be a gradient notion (ii), suggesting that a structural account as that of Fintel and Iatridou (2003) is unlikely:

(i) \{EVERY, Each, Any, Two $\}$ party guest(s) might be the murderer.

(ii) \{\#Everyone, ??every one of us, ?every single/last one of us\} might be the murderer.

${ }^{3} X$ may also be individual denoting, though we assume this triggers entity-to-event coercion. Thus, when the individual is sentient, ECP obviation is dependent on whether the coerced event is a doxastic state or a proffering event. In contrast, the ECP is obviated if the individual is a nonsentient information repository, as these may not participate in doxastic states (see section 3.2):
}

(i) According to the book, everyone might be the murderer. 
Strictly speaking, the ECP obviation diagnostic informs us only about the interpretation of epistemics in the scope of attitudes. If we are correct in claiming that the complements are always interpreted from an objective stance, then we should see a similar pattern of behavior with other subjectivity-sensitive terms.

One recently prominent class of such items are predicates of personal taste (POTs), whose extensions seem to be dependent on an evaluative perspective (Koebel 2002, Lasersohn 2005, Moltmann 2005, Stephenson 2007). ${ }^{4}$ Assuming a similar subjectivity divide, we should see more egocentric perspective for POTs in doxastic environments and a more community-wide acentric perspective in proffering environments. This is indeed the case:

a. John believed that this wine tastes oakey.

b. John claimed that this wine tastes oakey.

In (19a), the assessor for the oakiness of the wine is the attitude holder John; (19a) appears to discuss an opinion John has about his own preferences regarding the wine. In contrast, (19b) discusses an opinion he has about what "objectively" the wine tastes like. In other words, (19a) discusses a belief about a preference, while (19b) discusses a belief about a general consensus.

Given the preference vs. consensus distinction in (19), note the same kind of interpretive contrast is observable with epistemics (albeit less pronounced):

a. Holmes believed that the butler might be the murderer.

b. Holmes claimed that the butler might be the murderer.

Thus, (20a) describes what was possible with respect to Holmes' doxastic state at the time in question while (20b), speaking loosely, describes Holmes' assertion about how the world could be. ${ }^{5}$ In sum, we have seen two diagnostics on subjectivity of stance (ECP obedience, evaluative perspective for assessorsensitive terms) consistently differentiate doxastics and profferings, aligning the former with subjective stance and the latter with objective stance.

\subsection{Sentience requirements in attitudes of acceptance}

Having looked at how doxastics and profferings treat their complements, we now turn to their attitude holders. While doxastics require a sentient attitude holder, profferings do not $^{6}$ :

\footnotetext{
${ }^{4}$ Thanks to Kai von Fintel bringing up this kind of data.

${ }^{5}$ Prefiguring the analysis slightly, what (19b) actually reports is an attempt to make the possibility of the butler's guilt general consensus, and thus like (18b), objective.

${ }^{6}$ Note that a similar difference holds among bouletics and teleological attitudes, potentially complicating analyses of de se attitudes; we leave this topic for future research:
} 
(21) a. \#The book \{believes, thinks, knows \} that the Earth might be flat.

b. The book \{argues, claims, implies\} that the Earth might be flat.

While the source of this distinction is important in its own right, given the discussion in the previous section, the more relevant question is why subjectivity correlates with sentience and objectivity with non-sentience.

To begin our inquiry, consider the following list of proffering verbs, derived by the objectivity tests in the previous section:

argue, assert, assume, claim, convince, demonstrate, imply, presuppose, suggest

In addition to their common objective stances, the above verbs all report moves in discourse. While these moves may differ in terms of what is said (claim, imply, presuppose), intention (argue vs. claim), or success of the move (convince vs. suggest), as a class they all describe attempts to place their complement proposition in the common ground. If $p$ is in the common ground then it is mutually accepted (closed under acceptance by all discourse participants), and thus non-controversial, as all participants are aware that it is mutually accepted. We suggest, in line with Fintel and Gilles (2007) and Stephenson (2007), that this non-controversy is the source of the objective stance we diagnosed for proffering attitudes; things feel objective in a discourse inasmuch as the participants accept it and are aware that the others accept it. Thus proffering attitudes report attempts to make their complements non-controversial, and hence objective.

Given this characterization of proffering events, it follows that their attitude holders must be potential discourse participants. On first blush, books seem like poor conversational participants. We suggest, however, that metaphysical appearances to the contrary, certain inanimate attitude holders (those that are repositories of propositional information such as books or theories) can be discourse participants, though only with respect to generic conversations. Thus, while non-sentient attitude holders are admissible for proffering attitudes, they become unacceptable in episodic contexts (contra sentient attitude holders):

(23) \#The book claimed one hour ago that the Earth was flat.

In contrast, doxastic attitudes show neither of these characteristics. Being reports of belief, they require an element capable of cognitive states, and only sentient elements may do so. In addition, as belief is a private state, it makes no mention of common ground, and hence will not consider $\mathrm{p}$ with respect to a community's mutually accepted propositions.

The above precis amounts to the intuition of our proposal. While doxastic are belief reports, profferings are reports of discourse moves, that is, reports of

(i) The law \{hopes, aims to, \#wishes, ?wants\} to end poverty by 2020 . 
attempts of updating the common ground. This common ground component is responsible for the objective stance profferings take with respect to their complement. In the following subsection we will develop a formal analysis of these intuitions within the event-relative framework of section 2. Before doing so, we will deal with one complication in the dichotomous picture just presented. A subset of the verbs in (22) do not require their non-sentient subjects to be informational repositories, allowing a larger set of non-discourse participant (NDP) subjects:

(24) a. \#The time of death \{claims, argues\} that the butler is the murderer.

b. The time of death \{demonstrates, implies, suggests\} that the butler is the murderer.

Significantly, however, while these verbs show ECP obviation with informational repository subjects (a), with NDP subjects they obey the ECP (b), like doxastics:

(25) a. The book \{demonstrates, implies, suggests \} everyone might be the murderer.

b. \#The time of death \{demonstrates, implies, suggests $\}$ that everyone might be the murderer.

We suggest that the contrast in (25) indicates that NDP subjects involve a causative doxastic use of these predicates (cf. Chierchia 1989 re: persuade) in which an implicit experiencer may be generically quantified over (Bhatt \& Pancheva 2006, Moltmann 2005).

(26) \#The time of death suggests that everyone might be the murderer.

$\mathrm{GEN}_{\mathrm{x}}$ time of death causes $\mathrm{x}$ to believe everyone might be the murderer

Note that the same effect may be achieved even for informational repository subjects and an explicit experiencer:

(27) \#The book demonstrates to me that everyone might be the murderer. The book causes me to believe that everyone might be the murderer.

Thus, NDP subjects may appear with these verbs because they are ambiguous between a doxastic predicate with a non-subject, possibly covert attitude holder and a proffering predicate that involves a discourse move by the subject. ${ }^{7}$

\footnotetext{
${ }^{7}$ The possessor in nominalizations of these verbs must be a discourse participant, even though without the possessor the nominalization is ambiguous:

(i) The \{book, \#time of death\}'s suggestion that John is the murderer should be discounted.

(ii) The time of death suggests that John is the murderer, but that suggestion should be discounted.
} 


\subsection{Formal analysis}

Recall from the previous subsection our guiding intuition: proffering verbs induce objectivity of their complements because the complements are intended to become part of the common ground. That is, we are looking for the following relation between a sentence and its metalanguage paraphrase:

John claimed that the Earth is flat.

There was a claiming event e by John proposing to make [that the Earth is flat] common ground.

Our goal is to produce a semantics for profferings that arrives at the paraphrase above. As a starting point, recall the semantics for doxastics from section 2:

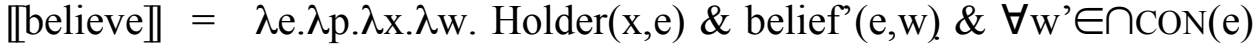

$$
\begin{aligned}
& {\left[\mathrm{p}\left(\mathrm{w}^{\prime}\right)=1\right] \text {, where } \cap \operatorname{CON}(\mathrm{e})=\operatorname{DOX}(\mathrm{tx} \operatorname{Holder}(\mathrm{x}, \mathrm{e}), \mathrm{w})}
\end{aligned}
$$

For believe, the complement clause is evaluated with respect to the content of the believing event, i.e., the doxastic alternatives of the subject, which comprises a private intensional domain. When the complement clause contains an epistemic modal, its event variable is bound by the doxastic event, thus making epistemics in the complement of a doxastic verb directly dependent on the content of the doxastic state, yielding a subjective stance:

(30) John believes that it might be raining.

There is a belief state of John s.t. [that it is raining] is compatible with his doxastic alternatives.

We have argued that profferings involve both an assertive event and the conversational goal of updating the common ground, and that the complement proposition should be evaluated with respect to that proposed common ground. Note that, as this common ground is a proposed common ground (i.e., non actual), it will be referable only in the scope of modal quantification. As it is one where the persuasive intention (goal) of the discourse move succeeds, the modality in question is teleological. To make the truth conditions more concrete, let us assume we have the metalanguage predicate Goal(e), which returns the conversational goal of event e. For proffering events, this will provide access to the proposed common ground that the embedded proposition is evaluated with respect to:

$$
\begin{aligned}
& \llbracket \text { claim } e p \rrbracket=\text { claim' }^{\prime}(\mathrm{e}) \& \forall \mathrm{w} \text { compatible with } \operatorname{Goal}(\mathrm{e}) \\
& \qquad\left[\forall \mathrm{w}^{\prime} \in \mathrm{CG}(\mathrm{w})\left[\mathrm{p}\left(\mathrm{w}^{\prime}\right)=1\right]\right]
\end{aligned}
$$


Corresponding to this proposed common ground is a proposed common ground state, call it $e_{C G-w,}$, which is the discourse state that would result from acceptance of $p$ by other discourse participants. We can now recast our entry in event terms. Claim describes a claiming event and introduces a new event, $e_{C G-w}$, namely the state of mutual acceptance that results from the goal of the claiming event:

【claim $e p \rrbracket=$ claim'(e) $\& \forall \mathrm{w}$ compatible with Goal(e)

$$
\left[\forall \mathrm{w}^{\prime} \in \cap \operatorname{CON}\left(e_{C G-w^{\prime}}\right)\left[\mathrm{p}\left(\mathrm{w}^{\prime}\right)=1\right]\right]
$$

Because the content of this event is objective, it will yield an objective stance for any epistemic modal whose event variable is bound by it. In the next section, we provide a compositional account which will allow us to relativize the modal to the event introduced by profferings $\left(e_{C G-w}\right)$.

\subsection{A revised clausal architecture}

The paraphrase in (32) has two hitherto unseen components: a new, derived event (a common ground acceptance state) and a quantification over teleologicallyaccessible worlds (in order to encode the various discourse futures). We must now determine how each of these novel components is introduced compositionally. We will assume that both functions are the responsibility of the proffering predicate itself.

However, recall that in order for the epistemic accessibility relations in the attitude complement to be dependent on the new event, their event arguments must be bound by a binder that connects with this new event. In the model for doxastics presented in section 2, this binder was the aspect that quantified over the doxastic event. This will not do here, as the proffering predicate introduces the new event. We propose to modify our clausal architecture by having acceptance complements be properties of events. The job of a predicate is to feed the correct event into the complement:

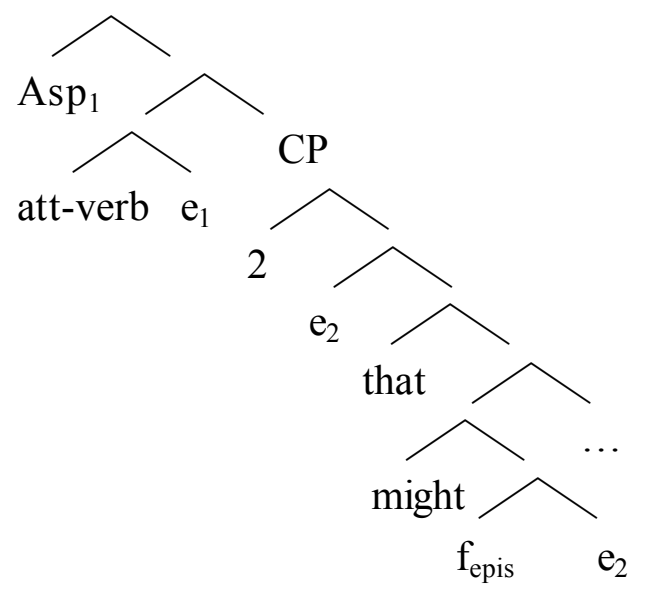


The difference between proffering and doxastic attitudes then will be what event they evaluate their complements with respect to. Doxastics will simply provide the acceptance state of the doxastic $\left(\mathrm{e}_{1}\right.$, above):

$$
\llbracket \text { believe } \rrbracket=\lambda \mathrm{e} \cdot \lambda \mathrm{P}_{\mathrm{et}} . \lambda \mathrm{x} . \lambda \mathrm{w} . \operatorname{Holder}(\mathrm{x}, \mathrm{e}) \& \text { belief'(e,w) \& } \mathrm{P}(\mathrm{e})=1 .
$$

In contrast, profferings provide an event that is computed inside the lexical entry:

$$
\begin{array}{r}
\llbracket \text { claim } \rrbracket=\lambda \mathrm{e} \cdot \lambda \mathrm{P}_{\mathrm{et} .} \cdot \lambda \mathrm{x} \cdot \lambda \mathrm{w} . \operatorname{Holder}(\mathrm{x}, \mathrm{e}) \& \operatorname{claim}(\mathrm{e}, \mathrm{w}) \& \\
\forall \mathrm{w}^{\prime} \in \operatorname{Goal}(\mathrm{e})\left[\mathrm{P}\left(\mathbf{e}_{\mathbf{C G}-\mathrm{w}^{\prime}}\right)=1\right] .
\end{array}
$$

Thus, while in (33) $\mathrm{f}_{\text {epis }}$ will always be evaluated with respect to $\operatorname{CON}\left(\mathrm{e}_{2}\right)$, if the attitude of acceptance is a proffering, it will be evaluated with respect to a modally quantified (i.e., projected) common ground acceptance state.

Note that neither of the entries in (34) and (35) involve the Hintikkan quantification accessible worlds; in (33) this is performed by the embedded modal accessibility relation. As it stands, then, the system cannot derive an interpretation for attitude complements without modals. Recall, however, that this is the same situation as with assertions without modals, where there is no overt item to relate the speech event to worlds of evaluation (cf. section 2). To solve that problem, Hacquard (2008) employed the ASSERT operator in (8) which quantified over worlds compatible with the content (i.e., acceptance state) of the speech event. Pursuing the parallelism between matrix and embedded clauses, $e_{2}$ requires a correspondent in embedded clauses. Following Kratzer (2006) and Moulton (2007), we assume that the complementizer (both in embedded and matrix clauses) is what relates acceptance events to worlds when there is no modal:

$$
\llbracket \text { that } \rrbracket=\lambda \mathrm{p} \cdot \lambda \mathrm{e}, \forall \mathrm{w}^{\prime} \in \cap \operatorname{CON}(\mathrm{e})\left[\mathrm{p}\left(\mathrm{w}^{\prime}\right)=1\right] .
$$

This gives us the following scheme for non-modalized complements:

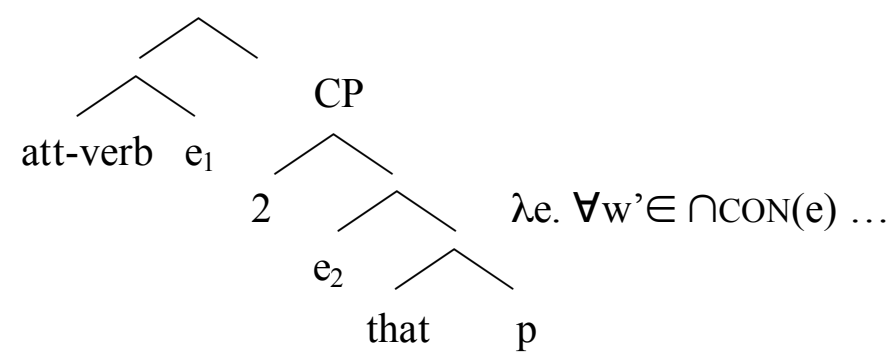

With these ingredients in place, we can now compute the truth conditions of 'John claims/believes that the earth is flat'. Note that due to the complementizer, the complement clause is already modal and merely needs an anchoring event:

$$
\text { [that the Earth is flat } \rrbracket=\lambda \text { e. } \forall w^{\prime \prime} \in \cap \operatorname{CON}(e)[\text { flat'(earth')(w')]. }
$$


Both attitude verbs supply that anchoring event. For believe, it is straightforward substitution:

(39) $\llbracket J o h n$ believe e that Earth is flat $\rrbracket=$ [believe $\rrbracket(e)(\llbracket$ that Earth is flat $\rrbracket(\llbracket J \rrbracket)$

$=\llbracket$ believe $\rrbracket(e)(\llbracket(38) \rrbracket)(\mathrm{j})$

$=\left[\lambda \mathrm{e} \cdot \lambda \mathrm{P}_{\varepsilon \mathrm{t}} \cdot \lambda \mathrm{x} . \lambda \mathrm{w} . \operatorname{Holder}(\mathrm{x}, \mathrm{e}) \&\right.$ belief'$\left.^{\prime}(\mathrm{e}, \mathrm{w}) \& \mathrm{P}(\mathrm{e})=1\right](\mathrm{e})(\llbracket(38) \rrbracket)(\mathrm{j})$

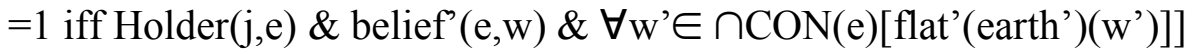

In contrast, the event provided by claim is quantified over to give teleologicallyaccessible common ground acceptance states:

(40) $\llbracket \mathrm{John}$ claim e that Earth is flat $\rrbracket=\llbracket$ claim $\rrbracket(\mathrm{e})(\llbracket$ that the Earth is flat $\rrbracket)(\llbracket \mathrm{J} \rrbracket)$

$=\llbracket$ claim $\rrbracket(e)(\llbracket(38) \rrbracket)(\mathrm{j})$

$=\left[\lambda \mathrm{e} \cdot \lambda \mathrm{P}_{\varepsilon} \mathrm{t} \cdot \lambda \mathrm{x} \cdot \lambda \mathrm{w} . \operatorname{Holder}(\mathrm{x}, \mathrm{e}) \&\right.$ claim' $(\mathrm{e}, \mathrm{w}) \&$

$$
\left.\forall w^{\prime} \in \operatorname{Goal}(e)\left[P\left(\mathbf{e}_{\mathbf{C G}-w^{\prime}}\right)=1\right]\right](e)(\llbracket(38) \rrbracket)(j)
$$

$=1$ iff Holder $(\mathrm{j}, \mathrm{e}) \&$ claim' $(\mathrm{e}, \mathrm{w}) \&$

$\forall w^{\prime} \in \operatorname{Goal}(\mathrm{e})\left[\forall^{\prime}, \in \cap \operatorname{CON}\left(\mathbf{e}_{\mathbf{C G}-\mathrm{w}}\right)[\right.$ flat'(earth')(w')] ]

Note that under this system, modals will again induce vacuous quantification, now bypassing the universal introduced by the complementizer. Thus, we have the following for the complement that the Earth might be flat:

(41) 【that the Earth might be flat $\rrbracket=\lambda$ e. $\forall w^{\prime} \in \cap \operatorname{CON}(\mathrm{e})$

$\left[\exists w^{\prime}, \in \cap \operatorname{CON}(e)[\right.$ flat'(earth')(w', $\left.\left.)\right]\right]$

$=\lambda$ e. $\exists \mathrm{w}, ' \in \cap \operatorname{CON}(\mathrm{e})[$ flat'(earth')(w')]

Substituting (40) for (37) in (38) and (39) produces the corresponding truth conditions for John believed/claimed that the Earth might be flat:

(42) 【John believe e that Earth might be flat $\rrbracket=1$ iff $\operatorname{Holder}(\mathrm{j}, \mathrm{e}) \&$ belief' $(\mathrm{e}, \mathrm{w})$

$\& \exists w^{\prime}, \in \cap \operatorname{CON}(\mathbf{e})[$ flat'(earth')(w', $\left.)\right]$

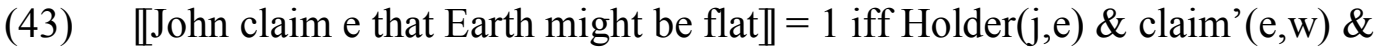

$$
\forall w^{\prime} \in \operatorname{Goal}(e)\left[\exists w^{\prime}, \in \cap \operatorname{CON}\left(\mathbf{e}_{\mathbf{C G}-\mathrm{w}}\right)[\text { flat'(earth')(w', }]\right.
$$

Stepping back from computation, let's summarize the analysis. The compositional mechanism for combining a proposition and its event of evaluation is uniform across matrix and embedded clauses, and is mediated by the complementizer. Like the speech event, attitudes of acceptance provide an event on which to anchor a CP complement clause. The difference between the two kinds of attitudes of acceptance lies in the type of anchoring event they supply: for doxastics, the event has subjective content (doxastic alternatives), for profferings, the event has objective content (common acceptance state). This explains the 
difference in behavior of subjectivity-sensitive terms like epistemics and predicates of personal taste in their complements.

\section{Speech acts and their reports}

If proffering attitudes are all discourse move reports, what is the relation between their semantics and the assertoric moves themselves? In this final section, we would like to tentatively consider this problem based on a curious dilemma. While proffering attitudes show ECP obviation, recall that in matrix contexts the ECP is obeyed without the tag objectively speaking. ${ }^{8}$ That is, the default interpretation of a matrix epistemic is subjective, even though proffering attitudes, which report assertive acts, are objective.

Our response to this worry is that proffering attitudes do not report assertions, but discourse moves, which are particular types of illocutionary events composed of an utterance of a proposition (assertion) paired with a goal to make that proposition common ground. It is this goal, which is encoded in the lexical semantics of proffering attitudes, that differentiates them from assertions. What the ECP obedience diagnostic tells us, then, is that bare assertions are semantically merely subjective utterances (alongside belief reports). While the goals of particular assertions might be to advance the discourse, this is part of the pragmatics of each utterance, not their semantics. In contrast, proffering attitudes describe both the literal content of an utterance (or sequence of utterances) and its (conventional) pragmatic function - common ground update. As such, they look at the ideal end result of such an utterance, which is "objective" in the sense assumed here. In other words, while the dynamics of assertion might result in common ground update (after acceptance by the participants), the statics of proffering attitudes makes mention of that update.

Though proffering attitudes do not permit reporting of the bare utterance, we suspect that the true verba dicendi (manner of speech verbs: say, scream, whisper) permit us to report the bare utterance, unadorned with conversational goals, at least under one of their manifold uses:

John said that the Earth might be flat.

Subj.: There is an event of speaking by J, s.t. [that the Earth is flat] is compatible with J's beliefs.

Obj.: There is an event of speaking by J, s.t. [that the Earth is flat] is compatible with the proposed common ground.

We leave further exploration of this tricky class of predicates to further research.

\footnotetext{
${ }^{8}$ For Tancredi might in the scope of objectively speaking isn't epistemic but circumstantial. We believe might is always epistemic. By epistemic we don't mean compatible with knowledge, nor necessarily beliefs, but possibilities and necessities given some informational content (rather than concrete circumstances tied to a particular event).
} 


\section{Conclusion}

This paper began with two motivating empirical puzzles about attitude predicates: (a) the distribution of those which license embedded epistemics and (b) the objective stance that proffering predicates project (as evidence by the ECP and POTs). Following Hacquard's (2006, 2008) closest-event relativity for modals, we argued that epistemics need to be licensed by a contentful event, which only attitude of acceptance events denote. In turning to (b), we argued that profferings describe discourse moves which aim to make certain claims common ground, hence objective. The content of their event is thus objective, in the sense of discourse non-controversial. Both these puzzles and our analysis argue (in line with Farkas 1992; Moltmann 2003; Kratzer 2006; Moulton 2007, a.o.) that the Hintikkan uniformism of attitude semantics is incorrect.

\section{References}

Alonso-Ovalle, Luis and Paula Menendez-Benito: 2008, 'Modal Indefinites', ms., UMass Boston and UMass Amherst.

Bhatt, Rajesh \& Roumyana Pancheva: 2006, 'Implicit Arguments', in The Blackwell Companion to Syntax, v. II, Blackwell, 554-584.

Chierchia, Gennaro: 1989, 'Anaphora and Attitudes De Se' in R. Bartsch, J. van Benthem and P. van Emde Boas (eds.) Language in context. Dordrecht: Foris.

Davidson, Donald: 1967, 'The Logical Form of Action Sentences', Reprinted in his Essays on Actions and Events, Oxford: Clarendon Press, 1980, pp. 105-122.

Drubig, Hans: 2001, 'On the syntactic form of epistemic modality', ms., university of Tübingen.

Farkas, Donka: 1992, 'On the semantics of subjunctive complements', in P. Hirschbühler \& K. Koerner (eds.) Romance Languages and Modern Linguistic Theory, 69-104, J. Benjamins.

von Fintel, Kai: 1994, Restrictions on Quantifier Domains, Ph.D. thesis. UMass Amherst.

von Fintel, Kai \& Tony Gillies: 2007, 'CIA Leaks' Philisophical Review 117(1):77-98.

von Fintel, Kai \& Sabine Iatridou: 2003, 'Epistemic Containment'. Linguistic Inquiry 34(2): 173-198.

Gunlogson, Christine: 2001, True to Form: Rising and Falling Declaratives as Questions in English. Ph.D. Thesis. UCSC.

Hacquard, Valentine: 2006, Aspects of Modality. Ph.D. Thesis. MIT. 
Hacquard, Valentine: 2008, 'On the Event-Relativity of Modals', $m s$., University of Maryland.

Halliday, Michael: 1970, 'Functional diversity in language as seen from a consideration of modality and mood in English'. Foundations of Language 6: $322-361$.

Hintikka, J.: 1962, Knowledge and Belief. Cornell University Press.

Koebel, Max: 2002, 'Faultless Disagreement' in Proceedings of the Aristotelian Society 104, 53-73.

Kratzer, Angelika: 1981, 'The notional category of modality' in H.-J. Eikmeyer and H. Rieser (eds.), Words, Worlds, and Contexts. New Approaches in Word Semantics. Berlin: de Gruyter.

Kratzer, Angelika: 2006, 'Decomposing Attitude Verbs'. Talk in honor of A. Mittwoch. The Hebrew University Jerusalem.

Lasersohn, Peter: 2005, 'Context Dependence, Disagreement, and Predicates of Personal Taste' Linguistics and Philosophy 28(6): 643-686.

Lyons, John: 1977, Semantics, Cambridge University Press.

Moltmann, Frederike: 2003, 'Propositional Attitudes without Propositions' Synthese 135.

Moltmann, Frederike: 2005, 'Relative truth and the first person', ms., IHPST /CNRS/ENS, Paris.

Moulton, Keir: 2007, 'Clausal Complementation and the wager-class' ms., UMass.

Palmer, Frank: 1986, Mood and Modality. Cambridge: Cambridge University Press.

Papafragou, Anna: 2006, 'Epistemic modality and truth conditions', Lingua 116.

Percus, Orin: 2000, 'Constraints on some other variables in syntax'. Natural Language Semantics 8, 173-229

Portner, Paul: 2008, Modality. Oxford: Oxford Univeristy Press.

Rooth, Matts: 1985, Association with Focus. PhD thesis, UMass Amherst.

Stalnaker, Robert: 1984, Inquiry, Cambridge, MA: The MIT Press

Stephenson, Tamina: 2007, 'Judge Dependence, Epistemic Modals, and Predicates of Personal Taste' Linguistics and Philosophy 30:4.

Swanson, Eric: 2006, 'Something might might mean', ms., University of Michigan.

Tancredi, Christopher: 2007, 'A Multi-Modal Theory of I-Semantics', ms., University of Tokyo.

Villalta, Elisabeth: 2000, 'Spanish subjunctive clauses require ordered alternatives', in Proceeding of SALT X. 